Marquette University

e-Publications@Marquette

Biomedical Engineering Faculty Research and

Publications

Biomedical Engineering, Department of

3-2009

\title{
Short-term Osteoclastic Activity Induced by Locally High \\ Concentrations of Recombinant Human Bone Morphogenetic \\ Protein-2 in a Cancellous Bone Environment
}

\author{
Jeffrey M. Toth \\ Marquette University, jeffrey.toth@marquette.edu \\ Scott D. Boden \\ Department of Veterans Affairs Medical Center \\ J. Kenneth Burkus \\ Medical College of Wisconsin \\ Jeffrey Badura \\ Medtronic Spinal and Biologics \\ Steve M. Peckham \\ Medtronic Spinal and Biologics
}

See next page for additional authors

Follow this and additional works at: https://epublications.marquette.edu/bioengin_fac

Part of the Biomedical Engineering and Bioengineering Commons

\section{Recommended Citation}

Toth, Jeffrey M.; Boden, Scott D.; Burkus, J. Kenneth; Badura, Jeffrey; Peckham, Steve M.; and McKay, William, "Short-term Osteoclastic Activity Induced by Locally High Concentrations of Recombinant Human Bone Morphogenetic Protein-2 in a Cancellous Bone Environment" (2009). Biomedical Engineering Faculty Research and Publications. 547.

https://epublications.marquette.edu/bioengin_fac/547 


\section{Authors}

Jeffrey M. Toth, Scott D. Boden, J. Kenneth Burkus, Jeffrey Badura, Steve M. Peckham, and William McKay

This article is available at e-Publications@Marquette: https://epublications.marquette.edu/bioengin_fac/547 
Marquette University

e-Publications@Marquette

\section{Biomedical Engineering Faculty Research and Publications/College of} Engineering

This paper is NOT THE PUBLISHED VERSION; but the author's final, peer-reviewed manuscript. The published version may be accessed by following the link in th citation below.

Spine, Vol. 34, No. 6 (March 15, 2009): 539-550. DOI. This article is (C Lippincott Williams \& Wilkins and permission has been granted for this version to appear in e-Publications@Marquette. Lippincott Williams \& Wilkins does not grant permission for this article to be further copied/distributed or hosted elsewhere without the express permission from Lippincott Williams \& Wilkins.

\section{Short-term Osteoclastic Activity Induced by Locally High Concentrations of Recombinant Human Bone Morphogenetic Protein-2 in a Cancellous Bone Environment}

Jeffrey M. Toth

Department of Orthopaedic Surgery, The Medical College of Wisconsin, Milwaukee, WI

Scott D. Boden

Department of Orthopaedic Surgery, The Emory Spine Center, Atlanta, GA

Kenneth J. Burkus

The Hughston Clinic, Columbus, GA

Jeffrey M. Badura

Medtronic Spinal and Biologics Business, Memphis, TN

Steven M. Peckham

Medtronic Spinal and Biologics Business, Memphis, TN

William F. McKay

Medtronic Spinal and Biologics Business, Memphis, TN 


\section{Author Information}

From the *Department of Orthopaedic Surgery, The Medical College of Wisconsin, Milwaukee, WI; +Department of Orthopaedic Surgery, The Emory Spine Center, Atlanta, GA; ++The Hughston Clinic, Columbus, GA; and [S]Medtronic Spinal and Biologics Business, Memphis, TN.

Acknowledgment date: July 14 2008. Acceptance date: October 9, 2008.

The manuscript submitted does not contain information about medical device(s)/drug(s).

Corporate/Industry funds were received in support of this work. One or more of the author(s) has/have received or will receive benefits for personal or professional use from a commercial party related directly or indirectly to the subject of this manuscript: e.g. honoraria, gift, consultancies, royalties, stocks, stock options, decision making position.

This animal study was conducted in compliance with the Guide for the Care and Use of Laboratory Animals published by the National Research Council.

Address correspondence and reprint requests to Jeffrey M. Toth, PhD, Department of Orthopaedic Surgery, Medical College of Wisconsin, 9200 W. Wisconsin Ave, Box 26099, Milwaukee, WI 53226-0099; E-mail: jtoth@mcw.edu.

\section{Abstract}

Study Design. An experimental study investigating osteoclastic activity induced by rhBMP-2 in sheep.

Objective. To examine the effects of increasing local rhBMP-2 concentration on osteoclastic response and peri-implant bone resorption.

Summary of Background Data. Level I clinical studies have established the safe and effective volume and concentration of rhBMP-2 delivered on an absorbable collagen sponge. However, peri-implant bone resorption appearing as decreased mineral density has been observed radiographically in rare instances after implantation of rhBMP-2 on an absorbable collagen sponge (rhBMP-2/ACS).

Methods. Bilateral corticocancellous defects were created in the distal femora of 30 adult sheep. Combinations of rhBMP-2/ACS implant volume (V) (1V = normal fill or $2 \mathrm{~V}=$ overfilled) and rhBMP-2 solution concentration $(x)(1 x=$ normal concentration or $3.5 x=$ hyperconcentrated) resulted in local rhBMP-2 concentrations of $0 x, 1 x, 2 x, 3.5 x$, and $7 x$ the estimated effective concentration for this model. Faxitron radiography, quantitative $\mathrm{CT}$, histology, and quantitative histomorphometry were conducted in a blinded fashion to analyze the effect of the treatments.

Results. At 1 week, the normal fill-normal concentration implants $(1 \mathrm{x})$ produced the least transient osteoclastic activity resulting in limited peri-implant resorption. Overfilled-hyperconcentrated implants $(2 x$, 3.5x) demonstrated moderate resorption zones. Overfilled-hyperconcentrated implants (7x) demonstrated extensive osteoclastic activity and marked resorption. Results at 4 and 8 weeks revealed dense osteoid and bone in the voids with progressive bony healing. Control defects showed no osteoclastic activity with little to no bony healing.

Conclusion. Increasing the local rhBMP-2 concentration by overfilling the defect with rhBMP-2/ACS or hyperconcen-trating the rhBMP-2 solution on the absorbable collagen sponge led to a concentrationdependent osteoclastic resorption of peri-implant bone. The osteoclastic effect was transient, and progressive healing took place over the 8-week survival period. 
Bone morphogenetic protein (BMP) is a potent osteoinductive morphogen capable of inducing de novo bone formation in ectopic sites and stimulating bony healing and repair in orthotopic bony sites. $\frac{1-3}{\text { In }}$ the late 1980s, the protein BMP-2 was isolated from human demineralized bone matrix (DBM) and cloned to produce recombinant human bone morphogenetic protein-2 (rhBMP-2). ${ }^{4}$ rhBMP-2 was the subject of extensive preclinical research that sought to identify the appropriate rhBMP-2 concentration and carrier to produce consistent and reproducible bone formation. $\frac{5-15}{3}$ Based on preclinical data from rat, rabbit, dog, ovine, and nonhuman primate models, it became apparent that higher concentrations of rhBMP-2 were required to induce consistent bone formation in higher phylogenetic order animals. $\frac{5-15}{\mathrm{In}}$ addition, it was demonstrated that a carrier was required to deliver the soluble rhBMP-2 protein to the graft site. $\frac{5,7,10-16}{1}$ The absorbable collagen sponge (ACS) carrier was found to incorporate sufficient amounts of rhBMP-2 while releasing it at a rate capable of initiating the bone formation cascade. $\frac{12-14}{14}$

In 2002, Poynton and Lane $\frac{17}{}$ published a safety profile related to the safety and use of BMPs in spinal fusion. They state, " [horizontal ellipsis] BMPs have a role in the regulation of bone turnover via coupled osteoblastic and osteoclastic activity. As with fracture healing, the osteoclastic resorption occurs before bone formation by osteoblasts. The exact effect of this in spinal fusion is not completely understood. However, large doses of BMP may lead to localized areas of resorption. This is not desirable in spinal fusion, and strategies to prevent this include careful control of dose and controlled release from the carrier."

Also in 2002 and following FDA-approved clinical studies, the combination of $1.5 \mathrm{mg} / \mathrm{mL}$ of rhBMP-2 on an ACS carrier (INFUSE Bone Graft, Medtronic Sofamor Danek, Memphis, TN) was approved as an autograft replacement in specific anterior lumbar interbody fusions (ALIF). INFUSE Bone Graft was subsequently approved for the treatment of open tibial fractures in 2004 and for certain oral maxillofacial applications in 2007. Since its introduction in 2002, INFUSE Bone Graft has been used successfully to induce spinal fusion. $18-$ $\underline{36}$ However, with expanded clinical use, rare instances of vertebral endplate or vertebral body resorption have been observed after lumbar interbody fusion with various interbody constructs. ${ }^{25,26,29,32,37,38}$ This resorptive phenomenon appears as decreased mineral density on computed tomography (CT) scans approximately 3 to 6 months after surgery. $\frac{25,26,29,32,37,38}{}$ Most often, the resorptive zones were transient and fusion subsequently occurred. $\underline{25,26,29,32}$

In 2005, Meisel et al reported "reduced mineral density" and "transient regional osteopenia" at 3 months in 17 patients treated with $12 \mathrm{mg}$ of rhBMP-2 in polyetheretherketone cages following LIF. 2 They indicated that these areas were resolved by 6 months. Also in 2005, Burkus et al25,26 reported that 14 of 79 (18\%) of patients developed "transient bone remodeling zones" between 3 and 12 months on CT after ALIF with INFUSE (8.4-12 $\mathrm{mg}[1.5 \mathrm{mg} / \mathrm{mL}])$ combined with threaded allograft bone dowels. Similarly, in 2006, Pradhan et al $\stackrel{38}{ }$ reported "aggressive resorption" of the graft and endplates after INFUSE use with ring allograft for ALIF, although the dose of rhBMP-2 was not reported. In a case report in 2006, Hansen and Sasso $\stackrel{29}{2}$ reported a resorptive response with rhBMP-2 $(4.2 \mathrm{mg}$ in $2.8 \mathrm{~mL}[1.5 \mathrm{mg} / \mathrm{mL}])$ after ALIF with ring allograft.

Although radiographic transient bone resorptive zones have been reported, cellular activity within these zones associated with the rhBMP-2 morphogen has not been characterized by histology. The goal of the current study was to use histology to characterize and describe chronological cellular activity within transient bone resorption zones associated with varying rhBMP-2/ACS concentrations and volumes in the ovine corticocancellous distal femur defect model. Quantitative computerized tomography (QCT), histology, and quantitative histomorphometry were used to quantify and characterize short-term osteoclastic response and bone resorption associated with hyperconcentrating and overfilling rhBMP-2/ACS in uniformly sized ovine corticocancellous bony defects at 3 separate postoperative time periods.

\section{Materials and Methods}

\section{Animal Model}

The ovine corticocancellous distal femur defect model is an established and validated model that has been used for the evaluation of bone grafts and bone void fillers. ${ }^{39-42}$ Unlike other models, this model provides for relatively uncomplicated surgical access, limited postoperative pain, and sufficient cancellous bone. In the 
current study, the ovine corticocancellous distal femur defect model was used to examine the short-term biologic activity of rhBMP-2/ACS under an IACUC-approved protocol. The animal study was conducted in compliance with the Guide for the Care and Use of Laboratory Animals published by the National Research Council.

\section{Animal Surgery}

Before surgery, animals were screened by radiography and hematology to rule out preexisting bony abnormalities and to exclude sheep with acute and chronic medical conditions. Thirty skeletally mature nongravid female sheep $(55-75 \mathrm{~kg}$ ) received bilateral cylindrical corticocancellous defects approximately 8.0 $\mathrm{mm}$ in diameter by $20.0 \mathrm{~mm}$ deep on the cranioventral surface of each lateral condyle. Defects were filled with 1 of 2 rhBMP-2/ACS implant volumes with 1 of 3 different rhBMP-2 solution concentrations as described in Table 1. Approximately $2.0 \mathrm{~mm}$ of the defect was filled with bone wax resulting in a bone defect volume of $1.0 \mathrm{~cm}^{3}$. The 60 defects were randomly assigned to 1 of the 5 treatment groups with a survival period of 1,4 , or 8 postoperative weeks. This resulted in 4 samples per treatment group per time point for analysis by computed tomography scan, high-resolution radiography, and histology, and quantitative histomorphometry. All analyses were conducted in a blinded fashion. In the ovine model, a dose concentration of $0.43 \mathrm{mg} / \mathrm{mL}$ of rhBMP-2 on ACS has been used in several studies. ${ }^{9,10,43,44}$ These studies provided the basis for selecting $0.43 \mathrm{mg} / \mathrm{mL}$ of rhBMP-2 on ACS as the normal dose concentration in sheep (1x in Table 1).

With the animal under general anesthesia, blunt dissection was performed, the periosteum elevated, and the lateral surface of the distal femur was exposed. A 2.5-mm Kirschner wire was inserted under fluoroscopic guidance to establish ideal positioning of the corticocancellous defects. An 8.0-mm diameter cannulated drill bit was placed over the Kirschner wire and advanced until an 8.0-mm diameter by 20.0-mm deep defect was created. The defect was then irrigated and dried. Following a randomization schedule, the appropriate treatment was prepared and inserted into the defect using forceps as shown in Figure 1. As directed in the instructions for preparation, the rhBMP-2 solution was allowed to soak on the ACS carrier for 15 minutes before implantation. Previous studies have demonstrated that $95 \%$ of the rhBMP- 2 is incorporated into the ACS following a 15-minute soak time and normal handling. $\underline{20}$ Thus, if fluid is displaced on implantation, most of the rhBMP-2 originally applied to the ACS should be present within the ACS carrier and thus contained within the defect. To contain the implant, the defect opening was covered with bone wax. Before closure, each animal received an injection of Marcaine into the surgical site and $1 \mathrm{~g}$ of cefazolin, intravenously. Postoperative monitoring was conducted and each animal was treated with analgesics for at least 5 days.

At the appropriate time points, the animals were killed by intravenous barbiturate overdose. Overlying soft tissues were sharply dissected from the defect site, and the operative femora were trimmed, labeled, and immersed in $10 \%$ neutral buffered formalin.

\section{CT Scan Analyses}

Images of all distal femora were acquired using computerized tomography (GE Discovery PET/CT scanner or GE LightSpeed Ultra Scanner; General Electric Co., Fairfield, CT). Distal femur specimens were positioned so the condyles faced toward the gantry to duplicate the positioning used to acquire true axial images in human patients. Specimens were centered and positioned to ensure the condyles were level. In addition to sagittal and anterior posterior scout images, axial volume images were acquired through the entire sample. Slices were acquired helically at $1.25-\mathrm{mm}$ thickness. Quantitative 3-dimensional volume measurements were made for the 1-week samples using embedded computed tomographic image analysis software (GE Advantage Windows Workstation; General Electric Co., Fairfield, CT).

\section{Radiography}

A high-resolution radiography unit (Faxitron model 43805, Hewlett Packard, McMinnville, OR) and highresolution film (Ektascan B/RA Film 4153; Kodak, Rochester, NY) were used to produce a high-resolution anteroposterior and lateral radiograph of all 60 femora. Using these radiographs as a guide, the defects on the distal portion of each femur were identified and grossly dissected to produce samples for histologic 
analyses. Four 4.5-mm thick sagittal slabs were produced for each femur as the femur was passed through the band saw. As sagittal slabs were produced from lateral to medial, the anatomic location of the sagittal slabs was labeled. An additional high-resolution radiograph of all 4 slabs from each of the defects associated with the 5 treatments at 1,4 , and 8 weeks was produced. After the slab radiographs were made, the slabs were trimmed to produce samples for histology. The entire defect with transient bone resorption and remodeling was preserved for histology; necessitating large brain slides in some cases.

\section{Decalcified Histology}

After fixation in $10 \%$ neutral buffered formalin, decalcification was carried out in $10 \%$ disodium ethylenediamine tetra acetate at a pH of 7.3 and 37[degrees]C. After decalcification was effected, samples were rinsed briefly in tap water, and processed using a paraffin infiltrator (Hypercenter, Shandon-Lipshaw, Chicago, IL) to dehydrate the specimens in graded alcohols, clear the specimens with xylene, and infiltrate the tissues with paraffin. Infiltrated tissues were then embedded in paraffin blocks and sectioned. Two slides stained with hematoxylin-eosin (H\&E), 2 slides stained with Mallory-Heidenhain, and 2 slides stained with Wright-Giemsa stain were produced for each paraffin block. Over 1400 histology slides were produced and analyzed.

\section{Quantitative Histomorphometry}

Quantitative histomorphometry was conducted to assess the extent of transient cancellous bone resorption and subsequent bony healing in all defects associated with the 5 treatments at the 3 time periods.

Quantitative histomorphometry was conducted using an image analysis system (Image Pro Plus Software version 5.0, Silver Spring, MD). Using the image analysis system, a high-resolution digital image of the entire defect as a whole was acquired from the medial stained histology slides. A millimeter scale present in the field allowed for spatial calibration of the image analysis system. The size of the defect (area in millimeters square) was measured on at least 2 medial sections for each of the 60 femora in the study. All data were normalized to $50.3 \mathrm{~mm}^{2}$, which corresponds to the area of an 8-mm defect.

\section{Statistical Analyses}

Analysis of variance (ANOVA) was used to model and compare QCT data and quantitative histomorphometry data. If the differences between all treatment groups were significant, further pair-wise comparisons of treatment groups were performed. $P$ values were adjusted using Tukey's method with regard to multiple testing. A 0.05 significance level was used for all tests.

\section{Results}

\section{Radiographic and Histologic-Histomorphometric Results at One Week}

\section{Postimplantation}

One-week quantitative computed tomography results, Faxitron radiographs, and quantitative histomorphometry showed that the buffer group (0x) demonstrated no peri-implant bone resorption (Figures 2-4). As seen in Table 2, QCT volume measurements showed an average defect size of $0.750 \mathrm{~cm}^{3}$ in the buffer control group, which was slightly less than the expected $1.0-\mathrm{cm}^{3}$ volume. As shown in Figure 3 , quantitative histomorphometry measurements made in the cancellous aspect of the defect in the buffer control group (0x) showed a normalized area of slightly less than 1. Histology from the buffer control group showed no osteoclastic activity and minimal osteoblastic activity, most likely associated with the creation and slight remodeling of the bony defect.

Of the groups containing rhBMP-2, the normal fill-normal concentration group (1x) induced the least amount of peri-implant resorption by QCT and quantitative histomorphometry at 1 week (Figure 3 ; Table 2). In most cases, the original defect boundaries were well preserved, although the defect size was increased in the samples. Decreased mineral density in peri-implant trabeculae was present in 2 of the 4 samples. As seen in Table 2, QCT measurements in the normal fill-normal concentration group (1x) resulted in an average defect size of $0.985 \mathrm{~cm}^{3}$, which was nearly identical to the $1.0-\mathrm{cm}^{3}$ defect size in the study 
design. As seen in Figure 3, quantitative histomorphometry measurements from the normal fill-normal concentration group (1x) were on average twice the original defect size in the study design in cancellous regions at 1 week. Mixed regions of osteoclastic resorption and osteoblastic activity with new osteoid were present at the periphery of the defects as shown in Figures 5A, B. Intramembranous bone formation with numerous hypertrophied osteoblasts at the periphery of the defect was present and occurring simultaneously with osteoclastic resorption as seen in Figure 5B. When osteoclasts were present, they were found at the periphery of the defect. Some osteoclasts were occupying resorption pits in the periimplant trabeculae (Figures $5 \mathrm{~A}, \mathrm{~B}$ ) or suspended within granulation tissues present in the peri-implant void spaces (Figure $5 \mathrm{C}$ ). Histology showed that peri-implant trabeculae had been resorbed or became osteopenic due to osteoclastic activity (Figures 4 and 5A). Consistent with early wound healing, both collagen sponge and granulation tissue were present within these defects.

In comparison, 1-week radiographs, QCT, histology, and quantitative histomorphometry from the overfillednormal concentration ( $2 x)$ and normal filled-hyperconcentrated (3.5x) groups demonstrated an increased amount of peri-implant bone resorption (Figures 2-4; Table 2). Qualitatively and quantitatively, these 2 groups had resorption zones of similar size, adjacent to the original defect and extending further into peri-implant cancellous bone compared with the normal fill-normal concentration (1x) defects. By QCT, the overfillednormal concentration ( $2 x)$ and normal filled-hyperconcentrated group $(3.5 x)$ were on an average $2 \mathrm{~cm}^{3}$, i.e., twice the size of the original defect size in the study design. Compared with the buffer control group, this resulted in $148 \%$ and $169 \%$ increases in average defect volume by QCT, respectively (Table 2). As seen in Figure 3 , quantitative histomorphometry measurements from the overfilled but normal concentration group as well as the hyperconcentrated but normal volume group at 1 week were on an average 21/2 times the size of the original defect size in the study design. Mixed regions of osteoclast resorption and osteoblastic activity with new osteoid were present at the periphery of the defect. Osteoclasts were found to occupy resorption pits in the peri-implant trabeculae or suspended within granulation tissue. Intramembranous bone formation at the periphery of the defect with numerous osteoblasts was present (igure 5B). Consistent with early wound healing, both collagen sponge and granulation tissue were present within these defects (Figure $\underline{5 D})$.

The overfilled and hyperconcentrated group (7x) showed significant peri-implant bone resorption by Faxitron radiographs, QCT, histology, and quantitative histomorphometry at 1 week (Figures 2-4; Table 2). The overfilled and hyperconcentrated group (7x) resulted in marked peri-implant bone resorption on CT scans (Figure 2). In many instances, the original defect boundary could not be identified, indicating that marked osteoclastic activity had occurred. By QCT, the average defect volume was $2.758 \mathrm{~cm}^{3}$, an approximate $268 \%$ increase compared with the buffer control (0x) group (Table 2). Pair-wise comparisons demonstrated that the average defect volume for the overfilled and hyperconcentrated group (7x) was statistically greater than the average defect volume for both the buffer control (0x) group and normal fill-normal concentration (1x) group (ANOVA, $P<0.05$ ). As seen in Figure 3 , quantitative histomorphometry measurements from the overfilled and hyperconcentrated group were on an average four and a half times the original defect size in the study design. Some defects in the overfilled and hyperconcentrated group were 7 times the initial defect size.

Statistically significant differences in defect size as measured in cancellous bone with quantitative histomorphometry were only found at the 1-week time period. Similar to the QCT measurements, the average normalized defect area in cancellous bone as measured by quantitative histomorphometry for the overfilled and hyperconcentrated (7x) group was greater than both the buffer control (0x) group and the normal fill-normal concentration (1x) group at 1 week (ANOVA, $P<0.05$ ). By histology, the original defect margin-boundary in the (7x) group could not be identified, indicating that marked osteoclastic activity had occurred within 1 week. Preexisting trabecular structures could be identified on macroscopic histology by collections of osteoclasts remaining after removal of the bony structure. Numerous osteoclasts, macrophages, and fibroblasts were present within the peri-implant voids and intramembranous ossification was observed at the periphery of the voids.

A common histologic finding for all groups at 1 week was a lack of cortical bone resorption. Bone resorption was most prominent in medial cancellous bony samples. Thus, quantitative histomorphometry measured on 
medial samples measured the greatest extent of bone resorption in cancellous bone, and not cortical bone loss. Another common finding for all groups at 1 week was the presence of ACS carrier in the original defect (Figure 5D). Minimal infiltration of the ACS had occurred at 1 week, although numerous macrophages and foreign body giant cells were located on the surface of the ACS, demonstrating cell-mediated degradation typical for this resorbable material. Lastly, seromas, hematomas, and florid osteoclastic resorption were frequently observed at 1 week.

\section{Radiographic and Histologic Results at Four Weeks Postimplantation}

Four-week CT scans seen in Figure 6 show bone remodeling limited to the periphery of the bony defects at 4 weeks in the buffer control (0x) group. As seen in Figures 6 and 7, progressive bony healing was noted in the 4-week CT scans and 4-week macroscopic histology in the rhBMP-2/ACS treatment groups. Histologically, no osteoclastic activity was present at 4 weeks for any treatment group, suggesting its transient occurrence with rhBMP-2/ACS. At 4 weeks, extensive osteoblastic activity, intramembranous ossification, and osteoid were present within the defects. This rapid osteoinductive event produced a new bone matrix that contained numerous thin trabeculae compared with the thicker native trabecular bone present in the metaphyseal portion of the distal femur. Differential staining indicated that some osteoid within the defect was partially mineralized. As seen in Figure 7, histologic cross-sections demonstrated that some of the cancellous regions of the defects were healing at 4 weeks.

As seen in Figure 3 , quantitative histomorphometry measurements at 4 weeks showed that only the buffer control (0x) and the normal fill-normal concentration (1x) groups were, on average, smaller than the original defect size in the study design in cancellous regions. Although quantitative histomorphometry demonstrated progressive bony healing from 1 to 4 weeks for the other 3 groups, the hyperconcentrated and overfilled groups still had defects that were on average larger than the original 8-mm defect size (Figure 3 ). Four-week computed tomography scans showed dense de novo bone formation within most peri-implant voids. Less residual ACS carrier was found within the defect at 4 weeks after surgery than at 1 week after surgery. Seromas and hematomas were still frequently observed at 4 weeks.

\section{Radiographic and Histologic Results at Eight Weeks Postimplantation}

CT scans showed bone remodeling limited to the periphery of the bony defects in the buffer control (0x) group at 8 weeks (Figure 8). Progressive bony healing was noted in the 8-week CT scans and 8-week macroscopic histology in the rhBMP-2/ACS treatment groups (Figures 8, 9). Histologically, no osteoclastic activity was present at 8 weeks for any treatment group, suggesting its transient occurrence with rhBMP2/ACS. At 8 weeks, extensive osteoblastic activity, intramembranous ossification, and osteoid were present within the defects. This rapid osteoinductive event produced a new bone matrix that contained numerous thin trabeculae compared with the native bone present in the metaphyseal region of the distal femur. Differential staining indicated that some osteoid within the defect was partially mineralized. Histologic cross-sections demonstrated that some cancellous regions of the defects were completely healed at 8 weeks. The buffer control group (0x) did not demonstrate significant osteoclastic or osteoblastic activity. As seen in Figure 3 , quantitative histomorphometry measurements showed that, on average, only the buffer control (0x) group was smaller in cancellous sampling than the surgically created 8-mm defect size at 8 weeks.

As seen in Figure 3 , quantitative histomorphometry clearly demonstrated progressive bony healing from 1 to 4 to 8 weeks. However, as seen in Figure 3 , all 4 of the rhBMP-2/ACS groups at 8 weeks still had defects that were, on average, larger than the original 8-mm corticocancellous bony defect. Computed tomography scans at 8 weeks showed an increase in bony healing of the defects and an increased radiopacity due to de novo bone that filled the previously created peri-implant voids (Figure 8). Seromas and hematomas were still frequently observed in the histology at 8 weeks (Figure 9). No ACS carrier remnants were observed in any of the samples at 8 weeks, demonstrating complete resorption of the ACS carrier.

\section{Discussion}


FDA-approved clinical investigations have examined rhBMP-2/ACS in threaded allograft bone dowels for ALIF surgery, in allograft rings for anterior cervical fusion, and in threaded titanium cages for ALIF and PLIF. $\underline{19-}$ $\underline{26,28}$ These clinical studies have shown that rhBMP-2/ACS can induce interbody spinal fusion when used with interbody spine fusion devices and bone grafts. Transient bone resorption was only observed in 1 of these FDA-approved clinical investigations. $\frac{25,26}{2}$ In that study, computed tomography scans at 3, 6, and 12 months showed that $18 \%$ (14 of 79) of the patients treated with rhBMP-2/ACS developed transient areas of bone remodeling within the vertebral bodies. These radiolucent remodeling zones were transient, resolving 12 to 24 months after surgery. A 99\% fusion rate occurred in this study at 24 months, despite the presence of these transient radiolucent remodeling zones. In that study, investigators placed 5.6 to $8 \mathrm{~cm}^{3}$ of rhBMP-2/ACS (8.4$12 \mathrm{mg}$ of rhBMP-2) at $1.5 \mathrm{mg} / \mathrm{cm}^{3}$ inside and between the 2 threaded allograft bone dowels in a single-level ALIF. ${ }^{25,26}$ The volume of rhBMP-2/ACS used per bone dowel was determined by the outer diameter of the construct. However, because the internal diameter of the dowels was dependent on the diameter of the donor's medullary canal, there was variability in each dowel's internal volume. This may have led to unanticipated overfilling of some bone dowels and a locally high rhBMP-2 concentration. Furthermore, the surgical technique for this procedure required more reaming of the endplates compared with tapered interbody fusion cages. $\underline{23}$ This may have resulted in increased exposure of mesenchymal stem cells, hematopoietic stem cells, and existing osteoclasts on trabecular bone to high doses of rhBMP-2.

Other clinical series and case reports have described transient bone resorption after the use of rhBMP-2 in interbody fusion procedures. ${ }^{29,32,37,38}$ Meisel et al 32 reported on a clinical series of 17 patients in which posterior lumbar interbody fusion was performed with polyetheretherketone vertebral body spacers and rhBMP-2/ACS. In their series, investigators placed $4 \mathrm{~cm}^{3}$ of rhBMP-2/ACS (6 mg rhBMP-2) into each of 2 vertebral body spacers. The internal volume of each interbody construct was $1.3 \mathrm{~cm}^{3}$. Overfilling the constructs in this manner produced a local rhBMP-2 concentration of approximately $4.6 \mathrm{mg} / \mathrm{cm}^{3}(6 \mathrm{mg}$ rhBMP-2/1.3 $\mathrm{cm}^{3}$ volume), which is more than 3 times the $1.5 \mathrm{mg} / \mathrm{cm}^{3}$ used in the previously cited Investigational Device Exemption (IDE) clinical trials involving interbody constructs. Their experience indicated that these radiographic observations proceeded to heal without incident during the 12-month follow-up and did not require revision surgery. In fact, it was reported that fusion was achieved in all patients by 6 months after surgery.

McClellan et $a / 37$ reported enhanced bony remodeling by CT scan at 3 months after surgery associated with the use of rhBMP-2 in 26 of 198 patients after transforaminal lumbar interbody fusion with an interbody construct and rhBMP-2/ACS. The volume of rhBMP-2/ACS used within and adjacent to the interbody construct ranged from 2.8 to $5.6 \mathrm{~cm}^{3}$ for single-level procedures and up to $8.0 \mathrm{~cm}^{3}$ for multilevel procedures. Resorptive defects in the vertebral bodies were noted in 22 levels. In the absence of histology, these defects were referred to as osteolytic defects and were graded as mild, moderate, or severe. Other published work has demonstrated the transient nature of these zones with some of the levels showing bony resorption progressing toward fusion, resulting in clinical success. $\frac{29,32,38}{}$ We believe that it is not accurate to describe these resorptive zones as osteolytic because (1) osteolytic lesions do not resolve within a short period, (2) osteolytic lesions do not actively remodel, and (3) osteolytic lesions do not generate significant new bone without further intervention. In the current ovine study, resorptive zones observed with rhBMP-2 were transient. QCT and quantitative histomorphometry showed that healing progressed with time and without additional intervention. In fact, osteoclastic activity was not observed in any of the treated defects at 4 weeks, regardless of treatment.

In addition to the clinical papers cited, a number of in vitro and in vivo animal studies have demonstrated the ability of BMP-2 to upregulate osteoclast activity and bone resorption in a dose-dependent manner. $\frac{45-}{}$

$\underline{49}$ Miyaji et al $\underline{48}$ showed that BMP-2 (at 0, 100, and $400[\mathrm{mu}] \mathrm{g} / \mathrm{mL}$ concentrations) caused a dose-dependent increase in dentin resorption through osteoclastic activity in vitro. Rodeo et al $l \underline{\text { fo }}$ found that the adjunctive use of rhBMP-2 on a collagen sponge accelerated tendon graft healing when placed into bone tunnels in the dog proximal tibia. However, they also noted osteoclast-mediated resorption of bone (evident as early as 7 days) in the high-dose rhBMP-2 group coupled with vigorous new bone formation adjacent to the bone tunnels. Similarly, Sumner et al ${ }^{51}$ investigated the use of rhBMP-2 to (1) enhance bone ingrowth into porous-coated 
implants and (2) to promote gap healing around the implants. They found that high doses of rhBMP-2 initially stimulated net bone resorption in adjacent host bone followed by bone formation. Taken together, these studies demonstrate that although the main mechanism of action of osteoinductive proteins is to differentiate stem cells and osteoprogenitor cells into osteoblasts, they can also upregulate osteoclastic activity at high dose concentrations.

Further work examining the effects of increasing local concentrations of rhBMP-2 on the ACS carrier could include additional short-term studies with more clinically relevant models, perhaps models of lumbar interbody fusion. The addition of bisphosphonates, effective as osteoclast and bone resorption inhibitors, could be used to examine their effects on the short-term osteoclastic response to rhBMP-2 and long-term fusion results.

Our study was performed to examine the effects of increasing local rhBMP-2 concentration on osteoclastic activity in a contained cancellous defect. This is the first study performed in a large animal model with analyses of both short-term computed tomography scans and histology. There are several possible limitations associated with this study. First, we experienced difficulty in creating a consistent $1.0-\mathrm{cm}^{3}$ defect in the ovine corticocancellous defect model. In determining the depth of the defect, the drill collar and guide were set to create a $20-\mathrm{mm}$ length defect on a flat bone surface. Because of the curved lateral surface of the distal femur, the drill sleeve may not have been flush with the bony surface, ultimately creating variability in the depth of the defect. This may have led to defect volumes less than $1.0 \mathrm{~cm}^{3}$ further simulating overfilling of the defect even in some of the normal fill samples. There also was variability associated with position of the defects with respect to the medullary canal. The increased availability of host bone cells (including hematopoietic stem cells) in the marrow of the medullary canal may have led to an increased osteoclastic response associated with high doses of rhBMP-2. In addition, the closer the defect was to the medullary canal, the less dense the trabecular bone structure appeared to be. This may have increased the amount of bone resorption compared with an osteoclastic response in a denser bony network. Second, the anatomic differences with respect to local trabecular structure of the sheep distal femur relative to the vertebral body are a limitation of this study. Third, as with any animal model, there may have been interanimal variability with respect to bone remodeling. Last, while the use of bone wax was effective to seal and contain the treatments within the bony defect in this model, it might have compressed the ACS implants and altered the healing environment or further hyperconcentrated the morphogen.

Despite these limitations, quantitative histomorphometry and QCT measurements from our study showed that increasing the local rhBMP-2 concentration by overfilling the defect with rhBMP-2/ACS or hyperconcentrating the rhBMP-2 solution on the absorbable collagen sponge led to a concentrationdependent increase in peri-implant cancellous bone resorption at 1 week. The osteoclastic resorption was transient, and histology demonstrated that osteoclastic activity was not observed at or after 4 weeks. By 4 weeks, osteoclastic activity in all groups had ceased and was replaced with osteoblastic activity and vigorous new intramembranous ossification. Progressive healing of the transient resorption defects took place over the 8-week survival period. Clinically, the transient resorptive response has infrequently been reported. Using the FDA-approved rhBMP-2 concentration and matching the volume of rhBMP-2/ACS with the volume of the bony defect or internal cavity of the device may limit the occurrence of transient bone resorption.

\section{Key Points}

* Increasing the local rhBMP-2 concentration by overfilling a bony defect with rhBMP-2/ACS or hyperconcentrating the rhBMP-2 solution led to concentration-dependent osteoclastic resorption of periimplant cancellous bone.

* Osteoclastic activity was transient, with no osteoclastic activity observed in any treatment at 4 weeks after surgery.

* Extensive osteoblastic activity and intramembranous bone formation was present at 4 weeks and continued through the 8-week survival period. 
* Using the FDA-approved rhBMP-2 concentration and matching the volume of rhBMP-2/ACS with the volume of desired bone formation may limit the occurrence of transient bone resorption.

\section{Acknowledgments}

The authors wish to acknowledge and sincerely thank Amy Rizzo, MT(ASCP) for her technical expertise and hard work in the histological processing of tissues, resulting in 1400 stained sections in support of this study.

\section{References}

1. Urist MR, Strates BS. Bone morphogenetic protein. J Dent Res 1971;50:1392-1406.

2. Urist MR, DeLange RJ, Finerman GA. Bone cell differentiation and growth factors. Science 1983;220:680-6.

3. Cheng $\mathrm{H}$, Jiang $\mathrm{W}$, Phillips $\mathrm{FM}$, et al. Osteogenic activity of the fourteen types of human bone morphogenetic proteins (BMPs). J Bone Joint Surg Am 2003;85-A:1544-52.

4. Wozney JM, Rosen V, Celeste AJ, et al. Novel regulators of bone formation: molecular clones and activities. Science 1988;242:1528-34.

5. Sandhu HS, Kanim LEA, Kabo JM, et al. Evaluation of rhBMP-2 with an OPLA carrier in a canine posterolateral (transverse process) spinal fusion model. Spine1995;20:2669-82.

6. Sandhu HS, Kanim LEA, Kabo MJ, et al. Effective doses of recombinant human bone morphogenetic protein2 in experimental spinal fusion. Spine 1996;21:2115-22.

7. Martin GJ Jr, Boden SD, Marone MA, et al. Posterolateral intertransverse process spinal arthrodesis with rhBMP-2 in a nonhuman primate: important lessons learned regarding dose, carrier, and safety. $J$ Spinal Disord 1999;12:179-86.

8. Hecht BP, Fischgrund JS, Herkowitz HN, et al. The use of recombinant human bone morphogenetic protein 2 (rhBMP-2) to promote spinal fusion in a nonhuman primate anterior interbody fusion model. Spine 1999;24: 629-36.

9. Sandhu HS, Toth JM, Diwan AD, et al. Histologic evaluation of the efficacy of rhBMP-2 compared with autograft bone in sheep spinal anterior interbody fusion. Spine 2002;27:567-75.

10. McKay B, Sandhu HS. Use of recombinant human bone morphogenetic protein-2 in spinal fusion applications. Spine 2002;27 (suppl 1):S66-85.

11. Boden SD. Overview of the biology of lumbar spine fusion and principles for selecting a bone graft substitute. Spine 2002;27 (suppl 1):S26-31.

12. Valentin-Opran A, Wozney J, Csimma C, et al. Clinical evaluation of recombinant human bone morphogenetic protein-2. Clin Orthop Relat Res 2002;395:110-20.

13. Geiger M, Li RH, Friess W. Collagen sponges for bone regeneration with rhBMP-2. Adv Drug Deliv Rev 2003;55:1613-29.

14. Seeherman H, Wozney J, Li R. Bone morphogenetic protein delivery systems. Spine 2002;27(suppl 1):S1623.

15. Wozney JM. Overview of bone morphogenetic proteins. Spine 2002;27(suppl 1):S2-8.

16. Hsu HP, Zanella JM, Peckham SM, et al. Comparing ectopic bone growth induced by rhBMP-2 on an absorbable collagen sponge in rat and rabbit models. J Orthop Res 2006;24:1660-9.

17. Poynton AR, Lane JM. Safety profile for the clinical use of bone morphogenetic proteins in the spine. Spine 2002;27(suppl 1):S40-8.

18. Anand N, Hamilton JF, Perri B, et al. Cantilever TLIF with structural allograft and rhBMP2 for correction and maintenance of segmental sagittal lordosis: long-term clinical, radiographic, and functional outcome. Spine 2006;31:E748-53.

19. Baskin DS, Ryan P, Sonntag V, et al. A prospective, randomized, controlled cervical fusion study using recombinant human bone morphogenetic protein- 2 with the CORNERSTONE-SR allograft ring and the ATLANTIS anterior cervical plate. Spine 2003;28:1219-25. 
20. Boden SD, Zdeblick TA, Sandhu HS, et al. The use of rhBMP-2 in interbody fusion cages. Definitive evidence of osteoinduction in humans: a preliminary report. Spine 2000;25:376-81.

21. Burkus JK. Bone morphogenetic proteins in anterior lumbar interbody fusion: old techniques and new technologies. Invited submission from the Joint Section Meeting on Disorders of the Spine and Peripheral Nerves. J Neurosurg Spine 2004;1:254-60.

22. Burkus JK, Dorchak JD, Sanders DL. Radiographic assessment of interbody fusion using recombinant human bone morphogenetic protein type 2. Spine2003;28:372-7.

23. Burkus JK, Gornet MF, Dickman CA, et al. Anterior lumbar interbody fusion using rhBMP-2 with tapered interbody cages. J Spinal Disord Tech 2002;15:337-49.

24. Burkus JK, Heim SE, Gornet MF, et al. Is INFUSE bone graft superior to autograft bone? An integrated analysis of clinical trials using the LT-CAGE lumbar tapered fusion device. J Spinal Disord Tech 2003;16:113-22.

25. Burkus JK, Sandhu HS, Gornet MF. Influence of rhBMP-2 on the healing patterns associated with allograft interbody constructs in comparison with autograft. Spine2006;31:775-81.

26. Burkus JK, Sandhu HS, Gornet MF, et al. Use of rhBMP-2 in combination with structural cortical allografts: clinical and radiographic outcomes in anterior lumbar spinal surgery. J Bone Joint Surg Am 2005;87:1205-12.

27. Carlisle E, Fischgrund JS. Bone morphogenetic proteins for spinal fusion. Spine J2005;5(suppl 6):240S-9S.

28. Haid RW Jr, Branch CL Jr, Alexander JT, et al. Posterior lumbar interbody fusion using recombinant human bone morphogenetic protein type 2 with cylindrical interbody cages. Spine J 2004;4:527-38; discussion 538-9.

29. Hansen SM, Sasso RC. Resorptive response of rhBMP2 simulating infection in an anterior lumbar interbody fusion with a femoral ring. J Spinal Disord Tech2006;19:130-4.

30. Kleeman TJ, Ahn UM, Talbot-Kleeman A. Laparoscopic anterior lumbar interbody fusion with rhBMP-2: a prospective study of clinical and radiographic outcomes. Spine 2001;26:2751-6

31. Lanman TH, Hopkins TJ. Lumbar interbody fusion after treatment with recombinant human bone morphogenetic protein-2 added to poly(L-lactide-co-D,L-lactide) bioresorbable implants. Neurosurg Focus 2004;16:E9.

32. Meisel HJ, Beier A, Hoell T, et al. Transient reduced mineral density associated with BMP-enhanced spinal fusion. [abstract] Proceedings of the NASS 20th Annual Meeting. Spine J 2005;55S-6S.

33. Mummaneni PV, Pan J, Haid RW, et al. Contribution of recombinant human bone morphogenetic protein2 to the rapid creation of interbody fusion when used in transforaminal lumbar interbody fusion: a preliminary report. Invited submission from the Joint Section Meeting on Disorders of the Spine and Peripheral Nerves, March 2004. J Neurosurg Spine 2004;1:19-23.

34. Resnick DK, Choudri TF, Dailey AT, et al. Guidelines for the performance of fusion procedures for degenerative disease of the lumbar spine. Part 16: bone graft extenders and substitutes. J Neurosurg Spine 2005;2:733-6.

35. Sasso RC, LeHuec JC, Shaffrey C. Iliac crest bone graft donor site pain after anterior lumbar interbody fusion: a prospective patient satisfaction outcome assessment. J Spinal Disord Tech 2005;18 suppl:S77-81.

36. Villavicencio AT, Burneikiene S, Nelson EL, et al. Safety of transforaminal lumbar interbody fusion and intervertebral recombinant human bone morphogenetic protein-2. J Neurosurg Spine 2005;3:436-43.

37. McClellan JW, Mulconrey DS, Forbes RJ, et al. Vertebral bone resorption after transforaminal lumbar interbody fusion with bone morphogenetic protein (rhBMP-2). J Spinal Disord Tech 2006;19:483-6.

38. Pradhan BB, Bae HW, Dawson EG, et al. Graft resorption with the use of bone morphogenetic protein: lessons from anterior lumbar interbody fusion using femoral ring allografts and recombinant human bone morphogenetic protein-2. Spine2006;31:E277-84.

39. Gisep A, Wieling R, Bohner M, et al. Resorption patterns of calcium-phosphate cements in bone. J Biomed Mater Res A 2003;66:532-40. 
40. Leniz $P$, Ripalda $P$, Forriol $F$. The incorporation of different sorts of cancellous bone graft and the reaction of the host bone. A histomorphometric study in sheep. Int Orthop 2004;28:2-6.

41. Nuss KM, Auer JA, Boos A, et al. An animal model in sheep for biocompatibility testing of biomaterials in cancellous bones. BMC Musculoskelet Disord 2006;7:67.

42. Walsh WR, Morberg $P, Y u Y$, et al. Response of a calcium sulfate bone graft substitute in a confined cancellous defect. Clin Orthop Relat Res 2003;406:228-36.

43. Toth JM, Wang M, Scifert J, et al. Evaluation of 70/30 D,L-PLA for use as a resorbable interbody fusion cage. Orthopedics 2002;25:S1131-40.

44. Toth JM, Wang M, Estes BT, et al. Polyetheretherketone (PEEK) as a biomaterial for spinal applications. Biomaterials 2006;27:324-34

45. Kanatani $\mathrm{M}$, Sugimoto $\mathrm{T}$, Kaji $\mathrm{H}$, et al. Stimulatory effect of bone morphogenetic protein-2 on osteoclastlike cell formation and bone-resorbing activity. J Bone Miner Res 1995;10:1681-90.

46. Kaneko H, Arakawa $\mathrm{T}$, Mano $\mathrm{H}$, et al. Direct stimulation of osteoclastic bone resorption by bone morphogenetic protein (BMP)-2 and expression of BMP receptors in mature osteoclasts. Bone 2000;27:479-86.

47. Koide $\mathrm{M}$, Murase $\mathrm{Y}$, Yamato $\mathrm{K}$, et al. Bone morphogenetic protein-2 enhances osteoclast formation mediated by interleukin-1 alpha through upregulation of osteoclast differentiation factor and cyclooxygenase-2. Biochem Biophys Res Commun 1999;259:97-102.

48. Miyaji H, Sugaya T, Kato K, et al. Dentin resorption and cementum-like tissue formation by bone morphogenetic protein application. J Periodontal Res 2006;41:311-5.

49. Wildemann B, Kadow-Romacker A, Lubberstedt M, et al. Differences in the fusion and resorption activity of human osteoclasts after stimulation with different growth factors released from a polylactide carrier. Calcif Tissue Int 2005;76:50-5.

50. Rodeo SA, Suzuki K, Deng X, et al. Use of recombinant human bone morphogenetic protein-2 to enhance tendon healing in a bone tunnel. Am J Sports Med 1999;27:476-88.

51. Sumner DR, Turner TM, Urban RM, et al. Locally delivered rhBMP-2 enhances bone ingrowth and gap healing in canine model. J Orthop Res 2004;22:58-65.

Key words: recombinant human bone morphogenetic protein-2 (rhBMP-2); spinal fusion; osteoclastic activity; osteoblastic activity; bone resorption

Table 1. Treatment Groups With Volume and Concentration of the Morphogen

\begin{tabular}{|c|c|c|}
\hline $\begin{array}{l}\text { Effective } \\
\text { Concentration }\end{array}$ & $\begin{array}{l}\text { Volume and } \\
\text { Concentration of } \\
\text { Morphogen }\end{array}$ & Treatment Group \\
\hline $0 \times$ & $\begin{array}{l}1 \mathrm{cc} \text { of }(0.00 \mathrm{mg} / \mathrm{mL}) \\
\mathrm{rhBMP}-2 / \mathrm{ACS}\end{array}$ & Buffer control group \\
\hline $1 \times$ & $\begin{array}{l}1 \mathrm{cc} \text { of }(0.43 \mathrm{mg} / \mathrm{mL}) \\
\text { rhBMP-2/ACS }\end{array}$ & $\begin{array}{l}\text { Normal volume and normal } \\
\text { concentration }\end{array}$ \\
\hline $2 \times$ & $\begin{array}{l}2 \mathrm{cc} \text { of }(0.43 \mathrm{mg} / \mathrm{mL}) \\
\text { rhBMP-2/ACS }\end{array}$ & $\begin{array}{l}\text { Overfilled and normal } \\
\text { concentration }\end{array}$ \\
\hline $3.5 \times$ & $\begin{array}{l}1 \mathrm{cc} \text { of }(1.5 \mathrm{mg} / \mathrm{mL}) \\
\mathrm{rhBMP}-2 / \mathrm{ACS}\end{array}$ & $\begin{array}{l}\text { Normal volume and } \\
\text { hyperconcentrated }\end{array}$ \\
\hline $7 \times$ & $\begin{array}{c}2 \mathrm{cc} \text { of }(1.5 \mathrm{mg} / \mathrm{mL}) \\
\mathrm{rhBMP}-2 / \mathrm{ACS}\end{array}$ & $\begin{array}{l}\text { Overfilled and } \\
\text { hyperconcentrated }\end{array}$ \\
\hline
\end{tabular}

Table 1. Treatment Groups With Volume and Concentration of the Morphogen

\begin{tabular}{|l|c|l|}
\hline $\begin{array}{l}\text { Effective } \\
\text { Concentration }\end{array}$ & $\begin{array}{c}\text { Volume and } \\
\text { Concentration of } \\
\text { Morphogen }\end{array}$ & Treatment Group \\
\hline $0 \mathrm{x}$ & $\begin{array}{c}1 \mathrm{cc} \text { of }(0.00 \mathrm{mg} / \mathrm{mL}) \\
\mathrm{rhBMP}-2 / \mathrm{ACS}\end{array}$ & Buffer control group \\
\hline
\end{tabular}




\begin{tabular}{|l|c|l|}
\hline $1 \mathrm{x}$ & $\begin{array}{c}1 \mathrm{cc} \text { of }(0.43 \mathrm{mg} / \mathrm{mL}) \\
\text { rhBMP-2/ACS }\end{array}$ & $\begin{array}{l}\text { Normal volume and normal } \\
\text { concentration }\end{array}$ \\
\hline $2 \mathrm{x}$ & $\begin{array}{c}2 \mathrm{cc} \text { of }(0.43 \mathrm{mg} / \mathrm{mL}) \\
\mathrm{rhBMP}-2 / \mathrm{ACS}\end{array}$ & $\begin{array}{l}\text { Overfilled and normal } \\
\text { concentration }\end{array}$ \\
\hline $3.5 \mathrm{x}$ & $\begin{array}{c}1 \mathrm{cc} \text { of }(1.5 \mathrm{mg} / \mathrm{mL}) \\
\mathrm{rhBMP}-2 / \mathrm{ACS}\end{array}$ & $\begin{array}{l}\text { Normal volume and } \\
\text { hyperconcentrated }\end{array}$ \\
\hline $7 \mathrm{x}$ & $\begin{array}{c}2 \mathrm{cc} \text { of }(1.5 \mathrm{mg} / \mathrm{mL}) \\
\mathrm{rhBMP}-2 / \mathrm{ACS}\end{array}$ & $\begin{array}{l}\text { Overfilled and } \\
\text { hyperconcentrated }\end{array}$ \\
\hline
\end{tabular}
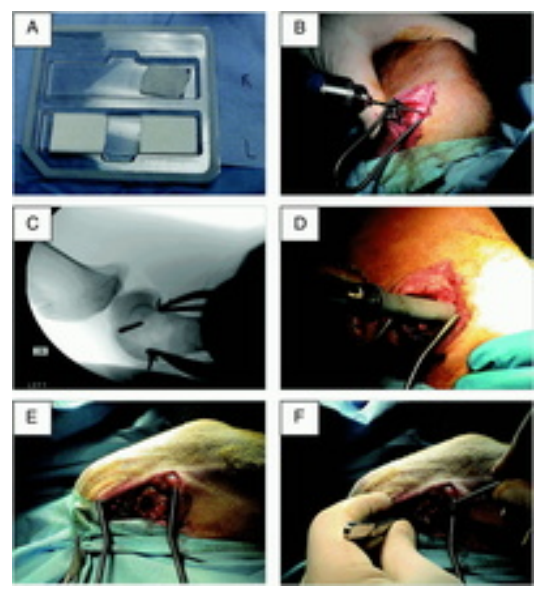

Figure 1. A, Implant preparation. B, Insertion of the Kirschner wire. C, Verification of Kirschner wire position using fluoroscopy. D, Creation of 8.0- x 20.0-mm defect using cannulated drill bit, drill collar, and drill sleeve. E, Empty defect following irrigation. $\mathbf{F}$, Insertion of implant into defect.

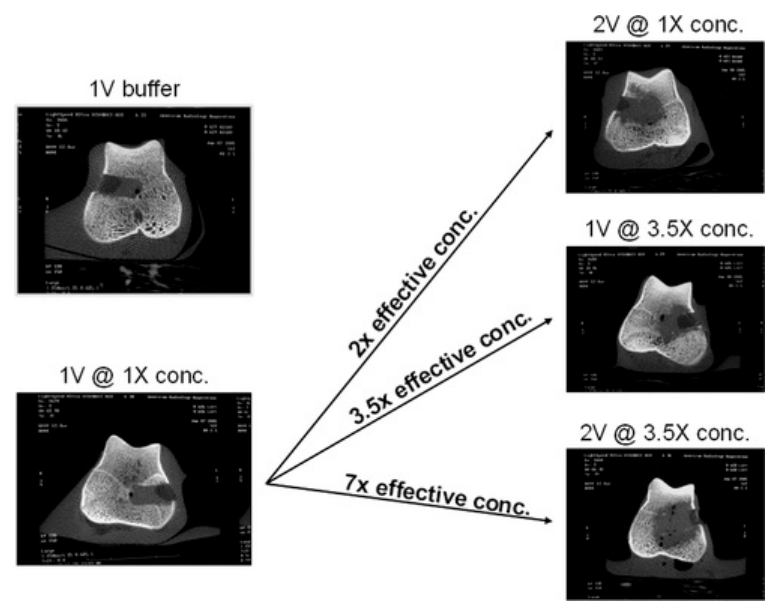

Figure 2. Axial computed tomography scans at 1 week show increased peri-implant cancellous bone resorption with increased effective concentration (conc.). Cortical bone resorption at the lateral aspect of the corticocancellous defect was not observed in any of the treatment groups. 


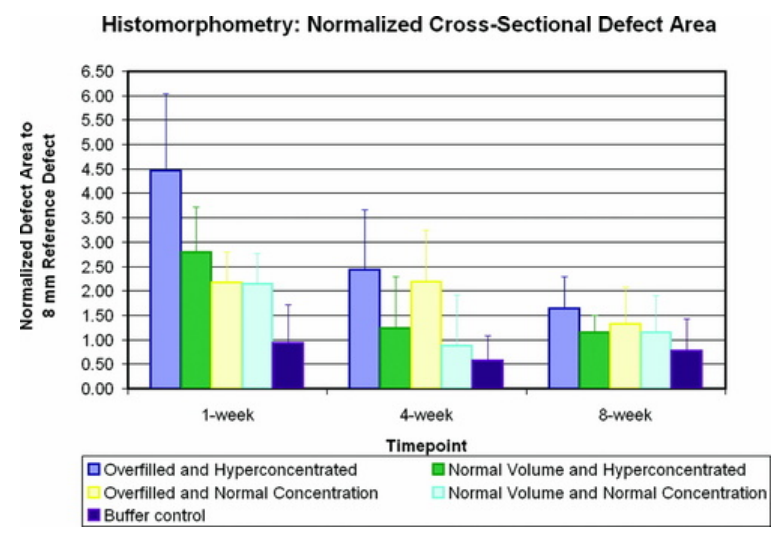

Figure 3. Quantitative histomorphometry results for medial cancellous bony samples for all treatments at all time periods. Data are normalized to an 8- $\mathrm{mm}$ defect that has an area of $50.3 \mathrm{~mm}^{2}$. Quantitative histomorphometry showed that increasing the total rhBMP-2 dose (by overfilling the defect or by hyperconcentrating rhBMP-2 on the ACS carrier) led to transient cancellous bone resorption followed by bony healing that progressed with time.

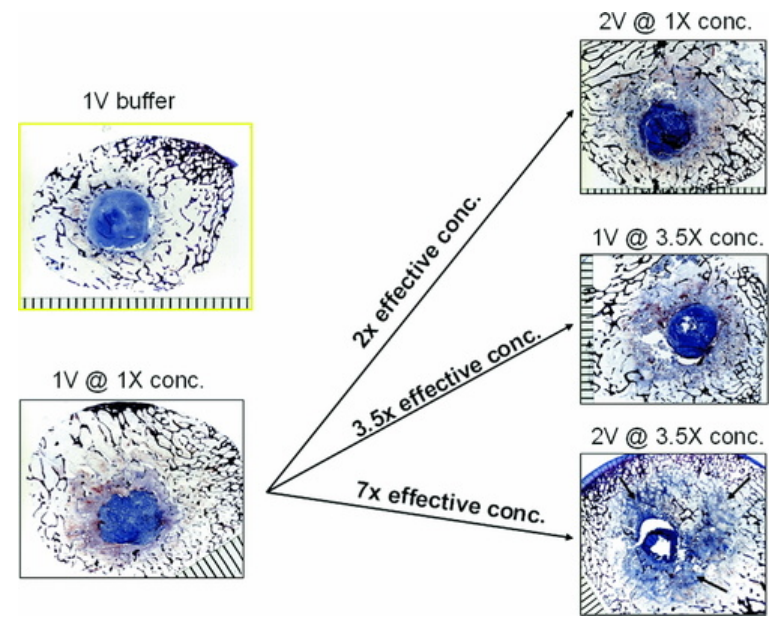

Figure 4. Decalcified macroscopic histology images (Mallory Heidenhain stain) at 1 week show increased trabecular bone resorption with increasing effective concentration (conc.). Mature native bone seen in dark red; dark blue within the original defect represents the ACS; and light blue represents granulation tissue and heightened cellular activity (osteoclasts). Note that in the overfilled and hyperconcentrated group, osteoclasts were found in peri-implant tissues following resorption of native trabecular bone (arrows). A millimeter ruler was placed in the field for scale reference.

Table 2. One-Week Postoperative Mean Defect Volumes $\left(\mathrm{cm}^{3}\right)$ and the Percentage Volume Increase Compared With the Buffer Control

\begin{tabular}{lcc}
\hline $\begin{array}{l}\text { Effective Concentration } \\
\text { (rhBMP-2) }\end{array}$ & Mean Defect Volume $\left(\mathrm{cm}^{3}\right)$ & $\begin{array}{c}\text { Percent Increase } \\
\text { to Control }\end{array}$ \\
\hline $0.0 \times$ (buffer control) & $0.749 \pm 0.150$ & NA \\
$1.0 \times$ & $0.985 \pm 0.243$ & $32 \%$ \\
$2.0 \times$ & $2.015 \pm 0.771$ & $169 \%$ \\
$3.5 \times$ & $1.858 \pm 0.808$ & $148 \%$ \\
$7.0 \times$ & $2.758 \pm 0.630$ & $268 \%$ \\
\hline
\end{tabular}

Table 2. One-Week Postoperative Mean Defect Volumes $\left(\mathrm{cm}^{3}\right)$ and the Percentage Volume Increase Compared With the Buffer Control

Effective Concentration (rhBMP-2) Mean Defect Volume $\left(\mathrm{cm}^{5}\right)$ Percent Increase to Control

$0.0 x$ (buffer control)

$1.0 x$

2.0x
$0.749 \pm 0.150$

$0.985 \pm 0.243$

$2.015 \pm 0.771$
NA

$32 \%$

$169 \%$ 

$3.5 x$

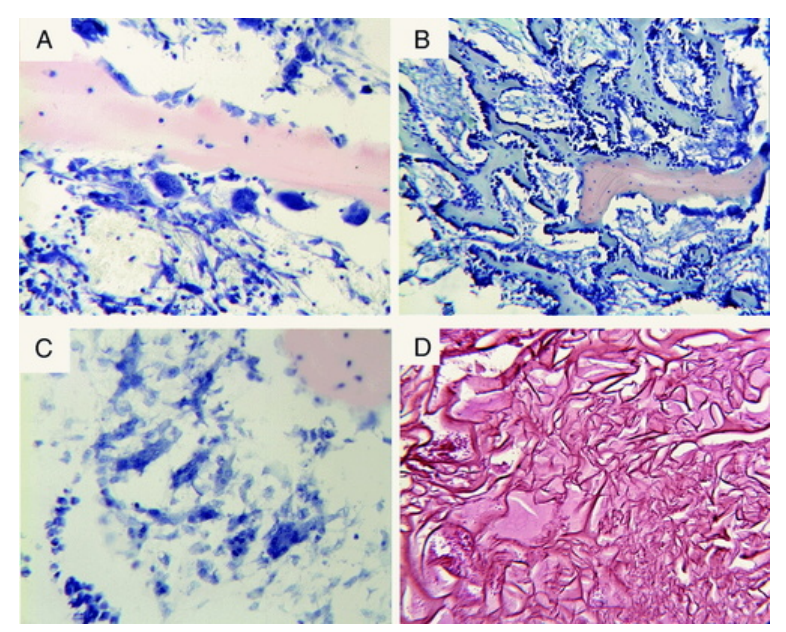

Figure 5. A, Osteoclastic activity and Howship's lacunae on native bone at the periphery of the bony defect in the $1 x$ group at 1 week after surgery (Wright-Giemsa stain, original magnification $=200 x$ ). B,Hypertrophied osteoblasts and intramembranous ossification (blue) on existing rarified trabeculae (pink) in the 2x group at 1 week after surgery. Osteoclasts are observed on the rarified trabeculae (pink) at 1 week. (Wright-Giemsa stain, original magnification $=$ 79x). C, Osteoclasts suspended within granulation tissue present in peri-implant void spaces in the $1 \mathrm{x}$ group at 1 week (Wright-Giemsa stain, original magnification $=200 x$ ). D, Residual collagen sponge with minimal cellular infiltration in the center of the bony defect in the $2 x$ group at 1 week (H\&E stain, original magnification $=79 x$ ).

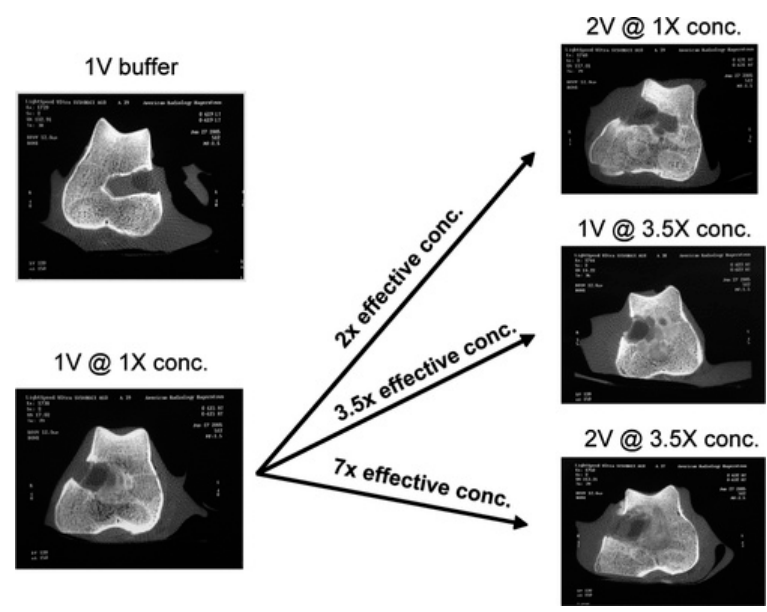

Figure 6. Axial computed tomography scans at 4 weeks show progressive healing of the defect. Bone wax that migrated into the defect may have limited bony healing at the defect opening.

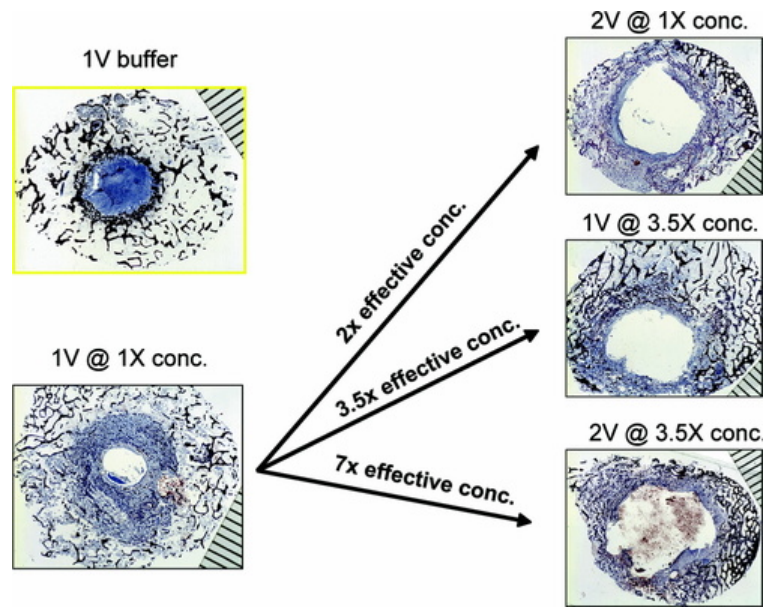


Figure 7. Decalcified macroscopic histology images (Mallory Heidenhain stain) at 4 weeks show dense new bone formation within the peri-implant voids and original defect. In these images, healing appears to be more complete in the normal fillnormal concentration (1x) group. A millimeter ruler was placed in the field for scale reference.



Figure 8. Axial computed tomography scans at 8 weeks show progressive healing of the defect. Bone wax that migrated into the defect may have limited bony healing at the defect opening.

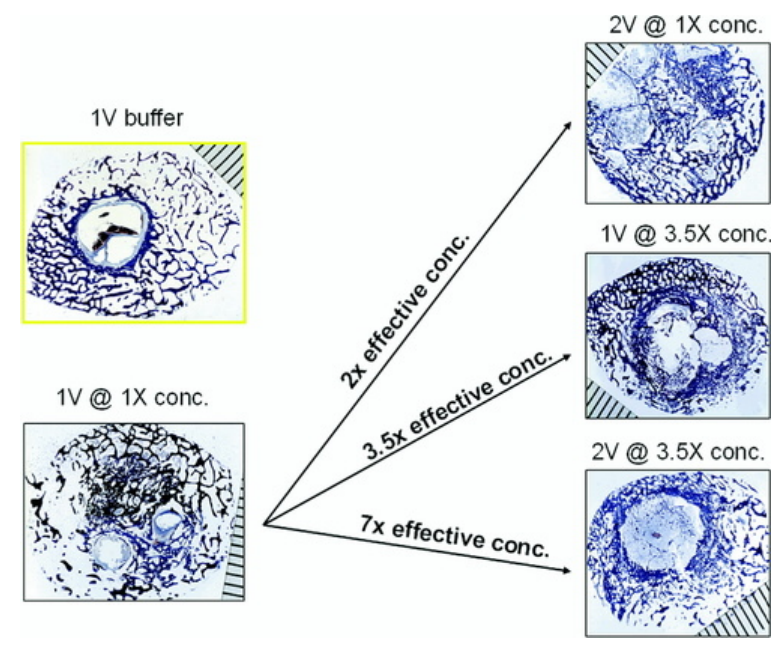

Figure 9. Decalcified macroscopic histology images (Mallory Heidenhain stain) at 8 weeks show dense new bone formation within the peri-implant voids and original defect. In these images, healing appears to be more complete in the normal fillnormal concentration (1x) group. A millimeter ruler was placed in the field for scale reference. 